\title{
Thermic Effect of Food at Rest, during Exercise, and after Exercise in Lean and Obese Men of Similar Body Weight
}

\author{
Karen R. Segal, Bernard Gutin, Åsa M. Nyman, and F. Xavier Pi-Sunyer \\ Department of Medicine, St. Luke's-Roosevelt Hospital Center, New York 10025; College of Physicians and Surgeons, Columbia \\ University, New York 10032; and the Applied Physiology Laboratory, Teachers College, Columbia University, New York 10027
}

\begin{abstract}
The thermic effect of food at rest, during $\mathbf{3 0}$ min of cycle ergometer exercise, and after exercise was studied in eight lean (mean \pm SEM, 10 $\pm 1 \%$ body fat, hydrostatically-determined) and eight obese men (30 $\pm 2 \%$ body fat). The lean and obese mean were matched with respect to age, height, weight, and body mass index (BMI) to determine the relationship between thermogenesis and body composition, independent of body weight. All men were overweight, defined as a BMI between $26-34$, but the obese had three times more body fat and significantly less lean body mass than the lean men. Metabolic rate was measured by indirect calorimetry under four conditions on separate mornings, in randomized order, after an overnight fast: (a) $3 \mathrm{~h}$ of rest in the postabsorptive state; (b) $3 \mathrm{~h}$ of rest after a 750-kcal mixed meal (14\% protein, $31.5 \%$ fat, and $54.5 \%$ carbohydrate); (c) during $30 \mathrm{~min}$ of cycling and for $3 \mathrm{~h}$ post exercise in the postabsorptive state; and $(d)$ during $30 \mathrm{~min}$ of cycling performed $30 \mathrm{~min}$ after the test meal and for $3 \mathrm{~h}$ post exercise. The thermic effect of food, which is the difference between postabsorptive and postprandial energy expenditure, was significantly higher for the lean than the obese men under the rest, post exercise, and exercise conditions: the increments in metabolic rate for the lean and obese men, respectively, were $48 \pm 7$ vs. $28 \pm 4$ kcal over 3 h rest $(P<0.05) ; 44 \pm 7$ vs. $16 \pm 5$ kcal over 3 h post exercise $(P$ $<0.05)$; and $19 \pm 3$ vs. $6 \pm 3 \mathrm{kcal}$ over $30 \mathrm{~min}$ of exercise $(P$ $<0.05)$. The thermic effect of food was significantly negatively related to body fat content under the rest $(r=-0.55)$, post exercise $(r=-0.66)$, and exercise $(r=-0.58)$ conditions. The results of this study indicate that for men of similar total body weight and BMI, body composition is a significant determinant of postprandial thermogenesis; the responses of obese are significantly blunted compared with those of lean men.
\end{abstract}

\section{Introduction}

The association between obesity and impaired thermogenesis, which is a diminished capacity for increased energy expenditure in response to certain stimuli, has received considerable investigative attention. A number of studies have shown that the rise in metabolic rate after ingestion of a meal, cold exposure, noradrenaline infusion, and the combination of a meal plus physical exercise, is significantly smaller in obese than lean humans

Address correspondence and reprint requests to Dr. Segal, Obesity Research Center, St. Luke's-Roosevelt Hospital Center, Amsterdam Ave. at 114 th St., New York 10025 .

Received for publication 6 February 1985 and in revised form 6 May 1985

J. Clin. Invest.

(C) The American Society for Clinical Investigation, Inc.

$0021-9738 / 85 / 09 / 1107 / 06 \$ 1.00$

Volume 76, September 1985, 1107-1112
(1-5). However, it has been argued that defective thermogenesis would play an insignificant role in the onset or persistence of human obesity because absolute energy expenditure at rest and under a variety of conditions is significantly greater in obese than nonobese subjects and the difference between their thermogenic responses is not great enough to compensate for the generally higher energy expenditure of the obese (6).

Obese people have a greater body fat content than normal weight subjects but they also have a greater total body weight and lean body mass (LBM) ${ }^{1}$ (7). Elevated body weight would account for a greater energy expenditure during activities such as walking or running in which the "work" done is related to the weight which is carried over a distance and a higher resting metabolic rate for the obese is thought to be related to their greater LBM since lean tissue has a greater metabolic rate than fat (8-9).

Since total body weight, body fat, and LBM all increase with increasing obesity and these body composition parameters are interrelated (9), it has not been possible to determine the independent relationship between body composition and thermogenesis. It is unclear whether observed metabolic differences between lean and obese subjects are specifically a function of differences in their fatness, since the usual lean controls for obese subjects are not merely nonobese but also lower in LBM and total body weight. The purpose of this study was to clarify the relationship between body composition and thermogenesis by comparing the responses of men of similar body weight and body mass index (BMI) but extremely different body composition.

\section{Methods}

Subjects. Eight lean and eight obese men between the ages of 20-32 participated in this study. The two groups were matched with respect to age, height, weight, and BMI. All subjects were overweight, which was defined as a BMI between 29-34 (10-11). The lean men were $<15 \%$ body fat and the obese men were $>25 \%$ body fat, as determined by underwater weighing (see below). The subjects were healthy with no history of metabolic or cardiovascular disease. An oral glucose tolerance test (OGTT) was administered (see below) to ensure that all subjects had normal glucose disposal. All subjects were weight-stable at the time of the study with no more than a $2 \mathrm{~kg}$ weight loss or gain over the 6 mo before the study. The subjects were instructed to consume a weightmaintenance diet containing at least $250 \mathrm{~g}$ carbohydrate/d several days before and throughout the duration of their participation in the study. Body weight was measured on every test day to confirm weight maintenance. The men were nonsmokers and were not taking any medications. None of the men engaged in regular aerobic exercise training but the lean men took part in strength training or participated in sports such as wrestling, football, judo, or power-lifting. These sports are considered to be primarily anaerobic in nature (12), although the training regimens

1. Abbreviations used in this paper: BMI, body mass index; BSA, body surface area; LBM, lean body mass; OGTT, oral glucose tolerance test; $\mathrm{RMR}$, resting metabolic rate; $\mathrm{VO}_{2}$ max, maximum aerobic power. 
for these sports may include an aerobic component. The written informed consent of all subjects was obtained and the protocol was approved by the Institutional Review Board of the St. Luke's-Roosevelt Institute for Health Sciences.

OGTT. An OGTT was performed after an overnight (12-h) fast. After a fasting blood sample was drawn, a $75-\mathrm{g}$ glucose load in $300 \mathrm{ml}$ lemon-flavored water was given and venous blood samples were drawn at 30-min intervals for $2 \mathrm{~h}$. The plasma was separated and analyzed for glucose and insulin. A Beckman glucose analyzer (Beckman Instruments, Inc., Fullerton, CA) was used for measuring plasma glucose (13). Plasma insulin was measured by radioimmunoassay with charcoal absorption with the use of a human insulin standard (14). The integrated areas under the glucose and insulin curves were calculated.

Densitometry. Body fat content and LBM were determined by densitometry. The subjects were tested in the morning after a 12-h fast. Body density was determined by hydrostatic weighing in a stainless steel tank in which a swing seat was suspended from a Chatillon $15-\mathrm{kg}$ scale. The subjects were submerged beneath the surface of the water while expiring maximally and remained as motionless as possible at the point of maximal expiration for roughly $5 \mathrm{~s}$ while underwater weight was recorded. After several practice trials to familiarize the subjects with the test procedure, 10 trials were performed. The estimated underwater weight was the highest value which was reproduced three times (15). Residual lung volume was estimated by means of the closed-circuit oxygen dilution method of Wilmore (16), with use of a Collins 9-liter spirometer (Warren E. Collins, Inc., Boston, MA) and a Hewlett Packard Vertek series nitrogen analyzer (Hewlett-Packard Co., Palo Alto, CA). Two trials were performed while the subjects assumed a sitting position that duplicated body position in the tank during underwater weighing. Body density was calculated from the formula of Goldman and Buskirk (17) and percent body fat was derived from body density by use of the Siri equation (18): percent fat $=4.95 /$ density -4.5 . LBM is the difference between total body weight and fat weight, where: fat weight $=$ total body weight $\times$ percent body fat.

Aerobic fitness test. Maximum aerobic power $\left(\mathrm{VO}_{2} \max \right)$ was determined by a continuous multistage exercise test on a Monark cycle ergometer (Monark, Varberg, Sweden). Before the test, time was allotted for the subjects to become familiar with cycling on an ergometer at a constant pedaling rate and to breathing through the apparatus used for metabolic measurements. The subjects began cycling at a rate of $50 \mathrm{rpm}$ with zero external resistance (unloaded cycling). A metronome was used to assist the subject in maintaining the proper pedaling rate. The work rate was increased in $25-\mathrm{W}$ increments every 2 min until volitional exhaustion was reached and the subject refused to continue despite vocal encouragement or until he was unable to maintain the pedaling rate. During the second minute at each work rate, ventilatory measurements were made by open-circuit respirometry with use of a Beckman metabolic measurement cart (Sensormedics Corp., Anaheim, CA), which includes a turbine volume transducer, a Beckman OM-11 polarographic oxygen $\left(\mathrm{O}_{2}\right)$ analyzer, and a Beckman LB-2 nondispersive infrared carbon dioxide $\left(\mathrm{CO}_{2}\right)$ analyzer (Beckman Instruments, Inc.). The subjects breathed through a Hans-Rudolf nonrebreathing valve and used a mouthpiece and noseclips. The gas analyzers were calibrated before and after each aerobic fitness test with $100 \%$ nitrogen, room air, and a gas mixture containing $4 \% \mathrm{CO}_{2}$ and $16 \% \mathrm{O}_{2}$. For each measurement, the fractional concentrations of $\mathrm{O}_{2}$ and $\mathrm{CO}_{2}\left(\mathrm{FEO}_{2}\right.$ and $\left.\mathrm{FECO}_{2}\right)$, oxygen consumption $\left(\mathrm{VO}_{2}\right)$, carbon dioxide production $\left(\mathrm{VCO}_{2}\right)$, minute ventilation $(\mathrm{VE})$, and the ventilatory equivalent for $\mathrm{O}_{2}\left(\mathrm{VE} / \mathrm{VO}_{2}\right)$ were obtained.

Submaximum aerobic fitness was determined by estimation of the ventilatory threshold from the test data. The ventilatory threshold is the highest work rate or $\mathrm{VO}_{2}$ before $\mathrm{VE}$ increases out of proportion to $\mathrm{VO}_{2}$ (19), owing to stimulation of ventilation by nonmetabolically produced $\mathrm{CO}_{2}$ which derives from the buffering of lactic acid (19). The fitness test data were used to provide descriptive information about the aerobic fitness level of the subjects and to determine the appropriate work rate for each subject during the thermogenesis tests which involved exercise.

Thermogenesis tests. The subjects refrained from strenuous activity on the day before each trial. They reported to the laboratory at 9:00 a.m. in the postabsorptive state after a 12-h fast on four nonconsecutive days; the days were nonconsecutive to avoid any carryover effects between treatments. On each day, after a 30-min rest period, base-line postabsorptive metabolic rate was measured. Three 5-min measurements were made within a 30-min period (at 5-10, 15-20, and 25-30 min) in order to avoid discomfort from continuous use of the mouthpiece. The three measures were averaged and the coefficient of variation across the three measurements was $<2 \%$. The laboratory was maintained at $24^{\circ} \mathrm{C}$ throughout the study. The gas analyzers were recalibrated (see above) every half-hour to correct for drift in the analyzers.

The order of the following four experimental treatments was randomized independently for each man:

(a) Postabsorptive resting metabolic rate (RMR) was measured for the last $6 \mathrm{~min}$ of every half-hour for $3 \mathrm{~h}$ while the subjects sat quietly. They were allowed to read or listen to music throughout the measurement period.

(b) Postprandial RMR was measured for the last 6 min of every halfhour for $3 \mathrm{~h}$ after the subjects consumed a 750-kcal liquid mixed meal (Ensure; Ross Laboratories, Columbus, $\mathrm{OH}$ ) which was $14 \%$ protein, $31.5 \%$ fat, and $54.5 \%$ carbohydrate. The test meal was consumed within $5 \mathrm{~min}$.

(c) Postabsorptive metabolic rate during and after exercise was measured. After the base-line RMR measurement, the subjects exercised for 30 min on a Monark cycle ergometer at the work rate just below each individual's ventilatory threshold. Metabolic rate during exercise was measured from 5 to 10,15 to 20 , and 25 to $30 \mathrm{~min}$ of the exercise period. Post exercise metabolic rate was measured during the fourth to tenth min post exercise and for the last $6 \mathrm{~min}$ of every half-hour for $3 \mathrm{~h}$ after exercise.

(d) Postprandial metabolic rate during and after exercise was measured following the procedures described above in $(c)$ except that the subjects consumed the $\mathbf{7 5 0}-\mathrm{kcal}$ test meal at $30 \mathrm{~min}$ before the start of exercise.

The exercise intensity was adjusted according to each subject's level of aerobic fitness because, owing to differences among the subjects in their level of aerobic fitness, a given constant work intensity may be extremely strenuous or too mild. This would result in differences in substrate utilization, blood lactate accumulation, and core temperature, and could influence the exercise- and postexercise-thermogenic responses. The work rate was assigned on the basis of each subject's ventilatory threshold, which reflects the highest work rate before the onset of anaerobiosis, instead of a percentage of the maximum, because the former is perhaps a more reliable measure since it is a physiological parameter while the latter depends on the motivation of the subject and his willingness and ability to exercise to exhaustion. Furthermore, Simon et al. (20) found that all subjects were able to complete $>30$ min of continuous exercise at the work rate just below the ventilatory threshold.

Variation among the subjects in the absolute work intensity should not have affected the thermic effect of food during exercise adversely; in a previous study (5), we compared the thermic effect of food during exercise at a constant work intensity for all subjects and a work rate assigned on the basis of each individual's ventilatory threshold and obtained very similar results.

For each metabolic measurement, the respiratory quotient $\left(\mathrm{VCO}_{2} /\right.$ $\mathrm{VO}_{2}$ ) was calculated and the result was converted to kilocalories by use of the Weir equation (21):

$\mathrm{kcal}=[(1.1 \times \mathrm{RQ})+3.9] \times \mathrm{VO}_{2}$

Analysis of data. Comparison of the thermic effect of food at rest and post exercise in the two groups was made by applying a $2 \times 2 \times 2$ $\times 6$ four-way analysis of variance with repeated measures (22) to the RMR from 0 to 180 min on the $4 \mathrm{~d}$ using group (lean or obese), food (meal or no meal trials), exercise (rest or post exercise), and time as the factors. Metabolic rate was expressed both as oxygen consumption and as caloric expenditure.

Comparison of the thermic effect of food during exercise in the two groups was made by applying a $2 \times 2$ two-way analysis of variance with 
repeated measures to the exercise metabolic rate data from the fasting and fed exercise trials using group (as above) and food (meal or no meal) as the factors.

Comparison of the thermic effect of food at rest with the thermic effect of food during exercise across the two groups was made by application of a $2 \times 2 \times 2$ three-way analysis of variance with repeated measures to the metabolic rate data obtained during the two 30-min exercise sessions and during the equivalent 30 -min periods on the two resting days. The factors in this analysis were group, food, and exercise (rest or exercise) with repeated measures on the second two factors.

For each of the above analyses, significant $F$ ratios from the analyses of variance were followed by post hoc comparisons using the appropriate error terms from the analyses of variance (22).

An analysis of variance with repeated measures was applied to the base-line RMR values obtained on the $4 \mathrm{~d}$ in order to determine whether there was significant day-to-day variation in fasting RMR. The reliability of repeated base-line RMR measurements was tested by the intraclass correlation method (22).

Comparisons of maximal and submaximal aerobic fitness, LBM, RMR (expressed in absolute form, and relative to body weight and LBM), and the results of the OGTT in the two groups were made by application of one-way analyses of variance to each of these variables.

The absolute increments in energy expenditure due to ingestion of the test meal were calculated for the sedentary, exercise, and post exercise trials by subtracting the fasting values from the fed values for appropriate time periods: $0-180 \mathrm{~min}$ for the resting trials with and without the test meal, the $\mathbf{3 0} \mathrm{min}$ of exercise on the two exercise trials for the thermic effect of food during exercise, and 0-180 minutes post exercise after the two exercise trials (with and without food) for the post exercise thermic effect of food. Correlations between these fed minus fasting difference scores, which represent the thermic effect of food at rest, during exercise, and post exercise, respectively, and variables such as LBM, percent body fat, submaximal and maximal aerobic fitness, and area under the glucose and insulin curves from the OGTT were calculated in order to examine the relationships among thermogenesis, body composition, aerobic fitness, and insulin and glucose responses to an oral glucose challenge.

Stepwise multivariate regression analyses were applied using the thermic effect of food at rest, during exercise, and post exercise as the dependent variables to study the independent effects of body composition, glucose tolerance, and level of physical fitness on thermogenesis.

For all statistical analyses the 0.05 level of significance was used.

\section{Results}

The subjects' characteristics are shown in Table I. The two groups were similar with respect to age, height, weight, BMI, and body surface area (BSA). There was almost a threefold difference between the groups in their body fat content, and LBM was more than $20 \%$ lower for the obese than the lean men. $\mathrm{VO}_{2}$ max was significantly lower for the obese men when expressed in absolute form (milliliters per minute) and relative to total body weight. Relative to $\mathrm{LBM}, \mathrm{VO}_{2}$ max was not significantly different for the two groups. The $\mathrm{VO}_{2}$ max values were within the range observed in healthy but not highly aerobically trained men of similar age (12). The ventilatory threshold occurred at a significantly lower power output for the obese than the lean men but at a similar percentage of $\mathrm{VO}_{2}$ max for the two groups (Table I).

The two groups did not differ reliably with respect to fasting plasma glucose or the area under the glucose curve but fasting plasma insulin and the area under the insulin curve were significantly lower for the lean than the obese men (Table I).

The fasting, base-line measurement of RMR did not vary significantly across the four treatment days for either group. The coefficient of variation in RMR across the $4 \mathrm{~d}$ was $2.9 \%$. The intraclass correlation coefficient was $r=0.99$, indicating that
Table I. Subject Characteristics*

\begin{tabular}{|c|c|c|c|}
\hline & Obese $(n=8)$ & Lean $(n=8)$ & $P$ \\
\hline Age & $25.4 \pm 1.6$ & $24.6 \pm 1.2$ & NS \\
\hline Weight $(k g)$ & $96.4 \pm 4.3$ & $95.0 \pm 4.3$ & NS \\
\hline Height $(\mathrm{cm})$ & $179 \pm 2$ & $180 \pm 3$ & NS \\
\hline $\operatorname{BMI}\left(k g / m^{2}\right)$ & $30.0 \pm .9$ & $29.6 \pm .6$ & NS \\
\hline $\operatorname{BSA}\left(m^{2}\right)$ & $2.15 \pm .06$ & $2.15 \pm .06$ & NS \\
\hline Percent fat & $30 \pm 2$ & $10 \pm 1$ & $<0.001$ \\
\hline LBM $(k g)$ & $67.4 \pm 2.7$ & $85.0 \pm 3.2$ & $<0.001$ \\
\hline \multicolumn{4}{|l|}{ Maximum aerobic power } \\
\hline Power output $(W)$ & $194 \pm 10$ & $231 \pm 33$ & $<0.05$ \\
\hline $\mathrm{VO}_{2}(\mathrm{ml} / \mathrm{min})$ & $2746 \pm 127$ & $3341 \pm 85$ & $<0.05$ \\
\hline$(\mathrm{ml} / \mathrm{kg} / \mathrm{min})$ & $28.9 \pm 1.9$ & $35.5 \pm 1.1$ & $<0.05$ \\
\hline$(\mathrm{ml} / \mathrm{kg} \mathrm{LBM} / \mathrm{min})$ & $41.2 \pm 2.4$ & $39.5 \pm 1.1$ & NS \\
\hline \multicolumn{4}{|l|}{ Ventilatory threshold } \\
\hline Power output ( $W$ ) & $75 \pm 7$ & $106 \pm 9$ & $<0.05$ \\
\hline $\mathrm{VO}_{2}(\mathrm{ml} / \mathrm{min})$ & $1427 \pm 87$ & $1642 \pm 86$ & $<0.05$ \\
\hline Percent $\mathrm{VO}_{2} \max$ & $52.2 \pm 2.8$ & $49.4 \pm 2.9$ & NS \\
\hline Resting metabolic rate $(\mathrm{kcal} / \mathrm{min})$ & $1.305 \pm .052$ & $1.479 \pm .061$ & $<0.05$ \\
\hline $\mathrm{VO}_{2}(\mathrm{ml} / \mathrm{min})$ & $268 \pm 10$ & $308 \pm 13$ & $<0.05$ \\
\hline$(\mathrm{ml} / \mathrm{kg} / \mathrm{min})$ & $2.80 \pm .13$ & $3.28 \pm .15$ & $<0.05$ \\
\hline$\left(\mathrm{ml} / \mathrm{m}^{2} B S A / \mathrm{min}\right)$ & $125 \pm 4$ & $144 \pm 6$ & $<0.05$ \\
\hline$(\mathrm{ml} / \mathrm{kg} \mathrm{LBM} / \mathrm{min})$ & $4.01 \pm .19$ & $3.65 \pm .17$ & NS \\
\hline Fasting insulin $(\mu U / m l)$ & $22 \pm 4$ & $13 \pm 2$ & $<0.05$ \\
\hline Fasting glucose $(m g / d l)$ & $82 \pm 2$ & $83 \pm 2$ & NS \\
\hline Insulin area $(\mu U / m l) \ddagger$ & $512 \pm 119$ & $216 \pm 33$ & $<0.05$ \\
\hline Glucose area $(m g / d l) \ddagger$ & $449 \pm 28$ & $403 \pm 19$ & NS \\
\hline
\end{tabular}

* Values expressed as mean \pm SEM.

$\ddagger$ Integrated over $2 \mathrm{~h}$ following a $75 \mathrm{~g}$ oral glucose load.

the measurement of RMR was extremely reliable. Base-line RMR, averaged over the four treatment days, was significantly lower for the obese than the lean men when expressed in absolute form (kilocalories per minute or $\mathrm{VO}_{2}$ milliliters per minute) and relative to total body weight and BSA. Relative to LBM, RMR was not significantly different for the two groups.

The analyses of variance yielded identical results when caloric expenditure and oxygen consumption were used as the dependent variables. Postabsorptive and postprandial $\mathrm{VO}_{2}$ under the resting and post exercise conditions are shown in Figs. 1 and 2. The four-way analysis of variance which used group, food (meal or no meal), level of exercise (rest or post exercise), and time (the half-hourly measurements) as the factors yielded a significant food $X$ group interaction, indicating that the thermic effect of food was significantly higher for the lean than the obese men. The exercise $\times$ food $\times$ time interaction was significant which reflects the different time course of the thermic effect of food under the resting compared with the post exercise condition. As shown in Fig. 2, under the post exercise condition, the thermic effect of food does not manifest as an increase in metabolic rate, but rather as a reduction in the rate of decline in metabolic rate after exercise. The exercise $\times$ food $\times$ group interaction was not significant which indicates that the difference between the thermic effect of food in the two groups was roughly the same under the resting and post exercise conditions. In other words, the thermic effect of food was greater for the lean compared with the obese group both at rest and post exercise, and the thermic effect of food was not significantly different between the post 


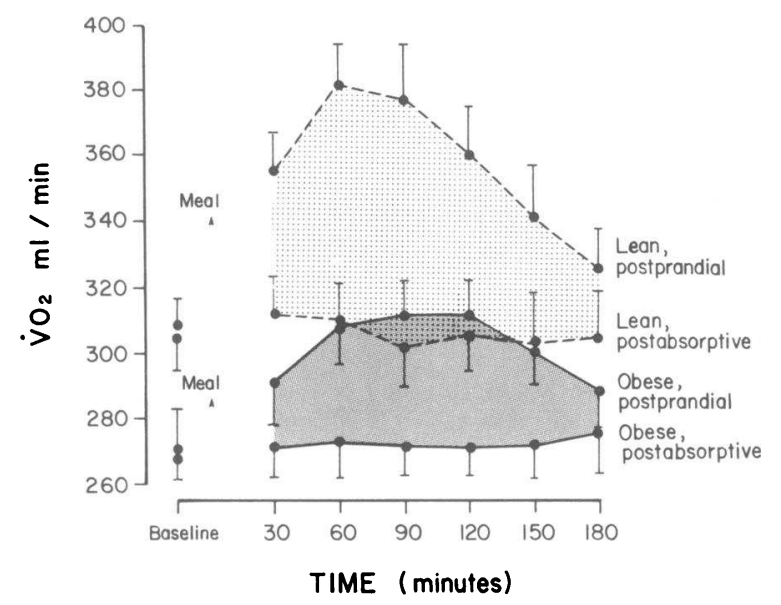

Figure 1. Resting metabolic rates of lean and obese men over $3 \mathrm{~h}$ in the postabsorptive state and after a 750-kcal mixed meal. The shaded areas represent the thermic effect of food for each group.

exercise and rest conditions for either group. Expressed as the increment in caloric expenditure over $3 \mathrm{~h}$, the thermic effect of food at rest was $48 \pm 7$ and $28 \pm 4 \mathrm{kcal}$ ( (mean \pm SEM) $(P<0.05)$ for the lean and obese men, respectively, and over 3-h post exercise, $44 \pm 7$ and $16 \pm 4 \mathrm{kcal}$ for the lean and obese men $(P$ $<0.05$ ), respectively.

The difference between the energy expended during exercise under the postprandial and postabsorptive conditions is shown in Fig. 3. The thermic effect of food during exercise was significantly greater for the lean than the obese men; during the 30min exercise bout, the difference in energy expenditure between the postprandial and postabsorptive treatments was $19 \pm 3$ vs. $6 \pm 3 \mathrm{kcal}$ for the lean and obese men $(P<0.05)$. The thermic effect of food was greater for the lean but not for the obese men during the 30-min exercise bout than during the equivalent 30 min period of rest.

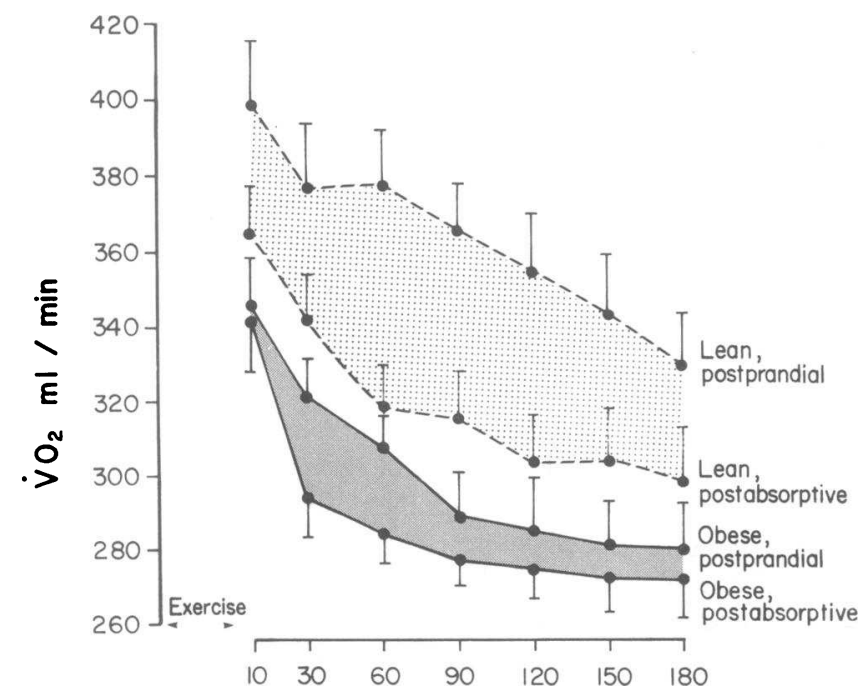

TIME AFTER EXERCISE ( $\mathrm{min}$ )

Figure 2. Post exercise metabolic rates of lean and obese men in the postabsorptive and postprandial state. The meal was given $30 \mathrm{~min}$ before the start of the 30-min exercise bout. The shaded areas represent the post exercise thermic effect of food for each group.

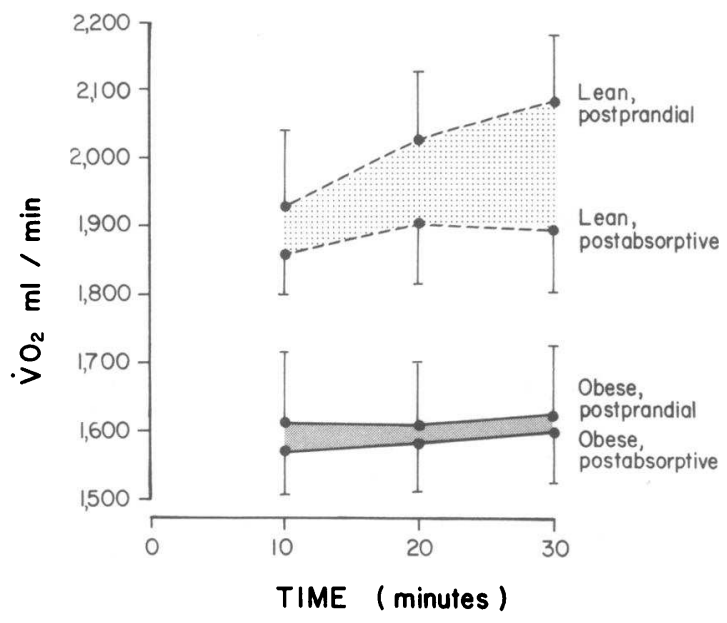

Figure 3. Metabolic rates of lean and obese men during $30 \mathrm{~min}$ of cycle ergometer exercise performed in the postabsorptive state and 30 min after the start of a 750-kcal mixed meal. The shaded areas represent the thermic effect of food during exercise for each group.

The peak increase in postprandial metabolic rate during the resting treatment occurred significantly later for the obese compared with the lean men $(95.6 \pm 9.4$ vs. $61.9 \pm 5.3 \mathrm{~min}$ after the meal). The time at which the peak increase in postprandial metabolic rate occurred was positively related to body fat content $(r=0.56)$ and negatively related to the thermic effect of food during exercise $(r=-0.48)$. Since the exercise bout was performed from 30 to $60 \mathrm{~min}$ after the start of the test meal, it is possible that the threefold lower thermic response during exercise for the obese compared with the lean men is related to their delayed response to the meal.

Percent fat was the best predictor (among body composition parameters, which included percent fat, LBM, body weight, BSA, and BMI; the OGTT results; and aerobic fitness parameters) of the thermic effect of food at rest $(r=-0.55)$, post exercise $(r$ $=-0.66)$, and during exercise $(r=-0.58)$. The correlation between aerobic fitness $\left(\mathrm{VO}_{2} \mathrm{max}\right)$ and the thermic effect of food was not statistically significant under either the resting $(r=0.41)$ or post exercise $(r=0.37)$ conditions. But aerobic fitness and body composition are somewhat confounded because the lean men were generally more fit than the obese men. When body fat was partialled out statistically, the correlation between aerobic fitness and the thermic effect of food was reduced to almost zero $(r=0.04)$. Fasting plasma insulin and the area under the 2-h insulin response curve following 75-g oral glucose appeared to be related negatively to the thermic effect of food; however, body fat content was roughly colinear with both fasting insulin level $(r=0.74)$ and insulin area $(r=0.84)$, and after body fat was taken into account, these variables were not significantly related to thermogenesis.

\section{Discussion}

It has been argued that defective thermogenesis could play only a small role in the onset and persistence of human obesity because, despite the significantly smaller thermogenic responses to a variety of stimuli which have been noted by a number of investigators, absolute energy expenditure is greater for obese compared with lean individuals under different conditions (6, 9). The reason for this is that in previous studies obese subjects 
were compared with nonobese controls who usually have not only less body fat but less LBM and lower total body weight and BSA.

In the present study we made use of a new model; instead of using a nonobese, nonoverweight control group, we compared the obese group with men who were overweight, according to their BMI, and matched to the obese men with respect to age, height, weight, and BMI. The two groups differed in their body composition such that one group was extremely lean with an elevated LBM accounting for their excess weight and the other was obese with body fat accounting for their excess weight.

The primary finding of this study was that the thermic effect of a 750-kcal mixed liquid meal was significantly smaller for the obese than the lean men at rest and during and after submaximal cycle ergometer exercise. And, contrary to the findings of other studies $(6,9)$, absolute energy expenditure was not greater for the obese than the lean men under any of the test conditions (Figs. 1-3). Thus, when the effect of excess weight per se is controlled for by use of a lean control group that is similar in degree of overweight to the obese group, obesity is associated with reduced energy expenditure and a diminished capacity for thermogenesis.

Recent studies have suggested that blunted thermogenesis is related to impaired glucose tolerance (23), a frequent complication of obesity, rather than obesity per se. In the present study, all subjects had normal glucose tolerance, according to the criteria of the National Diabetes Control Group (24). However, the obese subjects were hyperinsulinemic compared with the lean men even though fasting glucose and the 2 -h glucose response to a 75-g glucose load were similar for the two groups. Both fasting insulin and the area under the 2-h insulin curve were strongly related to body fat content. The larger insulin response for the obese subjects, suggestive of a degree of insulin resistance, is consistent with other studies $(25,26)$. This insulin resistance of the obese compared with the lean subjects may be related to their blunted thermogenic responses since an important role for insulin in thermogenesis has been suggested (27). A recent study demonstrated that insulin infusion increased the thermic effect of exercise in rat skeletal muscle (28). The results of the present study are not incompatible with the idea that insulin plays a role in thermogenesis: Ravussin et al. (29) found a decreased thermic response to infused glucose and insulin in insulin-resistant obese subjects. It is possible that the blunted thermic responses are related to the sensitivity to the level of insulin rather than the absolute quantity of insulin present.

The thermic effect of food was similar under the resting and post exercise conditions. However, the time course of the thermic effect of food differed between the two conditions: under the post exercise condition, a rise in metabolic rate during the postprandial treatment was masked by the post exercise decline in metabolic rate. Regardless, for both the lean and obese groups post exercise, RMR was significantly greater in the postprandial than the postabsorptive state even though this thermic effect of food was not greater post exercise than at rest.

There was a significant thermic effect of food during exercise for both groups as indicated by the greater energy expenditure during the 30 -min exercise bout in the postprandial than the postabsorptive state. For the lean but not the obese men, the thermic effect of food during exercise was greater than the thermic effect of food at rest during the equivalent 30-min period of the two rest trials (RMR from 30 to $60 \mathrm{~min}$ ). This is consistent with the results of other studies $(5,30,31)$, although some in- vestigators have not found a larger thermic effect of food during exercise than at rest even in normal weight subjects $(32,33)$. Differences among these studies in meal size and composition, and the timing of the meal and exercise may account for these conflicting findings.

The threefold lower thermic response during exercise for the obese compared with the lean men may be related to the delayed response of the obese men to the meal since the exercise bout was performed from 30 to $60 \mathrm{~min}$ after the start of the test meal and the peak increase in postprandial metabolic rate occurred 95.6 min after the meal for the obese group compared with 61.9 min for the lean group. Although the peak thermic response to food occurred later for the obese than the lean men, there is no evidence that the response is more prolonged in the obese subjects which would yield underestimations of the thermic effect of food over the 3-h resting and post exercise periods. In fact, as shown in Figs. 1 and 2, at the end of the third hour of measurement, the elevation in metabolic rate above the fasting, base-line level was greater, though not statistically different, for the lean than the obese subjects under both the resting and post-exercise conditions.

Recent studies have shown that the thermic effect of food is larger (34) and smaller (35) in highly aerobically trained compared with untrained individuals. In the present study, the thermic effect of food was not significantly correlated with level of aerobic fitness $\left(\mathrm{VO}_{2} \max \right)$. However, even though $\mathrm{VO}_{2} \max$ was significantly greater for the lean than the obese men, the aerobic fitness levels of the lean men were consistent with values obtained in untrained men and athletes who participate in sports that rely on muscle strength or speed more than on a high aerobic capacity.

It has been suggested that differences between thermic responses of lean and obese persons may be related to reduced sensitivity in the obese to the actions of thermogenic hormones stimulated by the ingestion of a meal or the confluence of food plus exercise or to a reduced thermogenic capacity in brown adipose tissue $(3,5,36,37)$. Another mechanism which might contribute to the lower thermic responses of the obese compared with the lean men in the present study is thermogenesis in skeletal muscle. It is likely that the far greater LBM for the lean group accounts for their greater RMR because of the greater energy expenditure of muscle compared with fat tissue. Protein turnover may account, in part, for the elevated energy expenditure (38), which in the present study, may be associated with increased LBM for the lean men. Protein synthesis is an energetically expensive process (39), accounting for $10-15 \%$ of basal metabolic rate (37). Therefore, even if the rate of protein turnover were similar for the obese and lean groups, absolute protein breakdown and synthesis would be greater for the overweight but lean men compared with the obese men, owing to the far greater muscle mass of the former group.

It has been proposed that skeletal muscle may be one site for nonshivering thermogenesis $(36,37)$. Thus, it is possible that the larger thermic responses of the lean men might be attributed in part to their greater skeletal muscle mass. However, further quantitative study of the capacity for thermogenesis within muscle tissue is needed before definitive statements of the role of LBM in thermogenesis can be made.

In conclusion, this study showed that RMR and the thermic effect of food at rest, during exercise, and post exercise are significantly greater for lean than obese men of similar height, weight, and degree of overweight, and that body composition is 
a significant determinant of thermogenesis; the capacity for thermogenesis is blunted in overly fat compared with overly muscular men.

\section{Acknowledgments}

This study was supported in part by a Biomedical Research Support grant from Teachers College, Columbia University and by the National Institutes of Health grant AM26687.

\section{References}

1. James, W. P. T., and P. Trayhurn. 1981. Thermogenesis and obesity. Br. Med. Bull. 37:43-48.

2. Jequier, E., P. Pittet, and P. H. Gygax. 1978. Thermic effect of glucose and thermal body insulation in lean and obese subjects: a calorimetric approach. Proc. Nutr. Soc. 37:45-53.

3. Jung, R. T., P. S. Shetty, and W. P. T. James. 1979. Reduced thermogenesis in obesity. Nature (Lond.). 279:322-323.

4. Shetty, P. S., R. T. Jung, W. P. T. James, M. A. Barrand, and B. A. Callingham. 1981. Postprandial thermogenesis in obesity. Clin. Sci. 60:519-525.

5. Segal, K. R., and B. Gutin. 1983. Thermic effects of food and exercise in lean and obese women. Metab. Clin. Exp. 32:581-589.

6. Blaza, S., and J. S. Garrow. 1983. Thermogenic response to temperature, exercise and food stimuli in lean and obese women, studied by 24-hour direct calorimetry. Br. J. Nutr. 49:171-180.

7. Forbes, G. B., and S. L. Welle. 1982. Lean body mass in obesity. Int. J. Obesity. 7:1073-1079.

8. James, W. P. T., K. Bailes, H. L. Davies, and M. J. Dauncey. 1978. Elevated metabolic rates in obesity. Lancet. I:1122-1125.

9. Ravussin, E., B. Burnand, Y. Schutz, and E. Jequier. 1982. Twentyfour hour energy expenditure and resting metabolic rate in obese, moderately obese, and control subjects. Am. J. Clin. Nutr. 35:566-573.

10. Bray, G. A. 1978. Definition, measurement, and classification of the syndromes of obesity. Int. J. Obesity. 2:99-112.

11. Thomas, A. E., D. A. McKay, and M. B. Cutlip. 1976. A nomograph method for assessing body weight. Am. J. Clin. Nutr. 29:302-304.

12. McArdle, W. D., F. I. Katch, and V. I. Katch. 1981. Exercise Physiology: Energy, Nutrition, and Human Performance. Lea and Febiger, Philadelphia, PA. 80-117.

13. Hugget, A. S., and D. A. Nixon. 1957. Use of glucose oxidase, peroxidase, and $O$-dianisidine in determination of blood and urinary glucose. Lancet. II:368-370.

14. Herbert, V., K. S. Lau, C. W. Gottlieb, and S. J. Bleicher. 1965. Coated charcoal immunoassay of insulin. J. Clin. Endocrinol. Metab. 25:1375-1384.

15. Behnke, A. R., and J. H. Wilmore. 1974. Evaluation of Body Build and Composition. Prentice Hall, Englewood Cliffs, NJ.

16. Wilmore, J. H. 1969. A simplified method for determination of residual lung volume. J. Appl. Physiol. 27:96-100.

17. Goldman, R. F., and E. R. Buskirk. 1961. Body volume measurement by underwater weighing: description of a method. In Techniques for Measuring Body Composition. J. Brozek and A. Henschel, editors. National Academy of Science, Washington, DC. 78-89.

18. Siri, W. E. 1961. Body composition from fluid spaces and density: analysis of methods. In Techniques for Measuring Body Composition.
J. Brozek and A. Henschel, editors. National Academy of Science, Washington, DC. 223-244.

19. Wasserman, K., and B. J. Whipp. 1975. Exercise physiology in health and disease. Am. Rev. Respir. Dis. 112:219-249.

20. Simon, J., J. L. Young, B. Gutin, D. K. Blood, and R. B. Case. 1983. Lactate accumulation relative to the anaerobic and respiratory compensation thresholds. J. Appl. Physiol. 54:13-17.

21. Weir, J. B. 1949. New method for calculating metabolic rate with special reference to protein metabolism. J. Physiol. 109:1-9.

22. Winer, B. J. 1971. Statistical Principles in Experimental Design. Second ed. McGraw-Hill, New York. 283-289, 571-577.

23. Golay, A., Y. Schutz, H. U. Meyer, D. Thiebaud, B. Curchcod, E. Maeder, J. P. Felber, and E. Jequier. 1982. Glucose induced thermogenesis in nondiabetic and diabetic obese subjects. Diabetes. 31:10231028 .

24. National Diabetes Data Group. 1979. Classification and diagnosis of diabetes mellitus and other categories of glucose tolerance. Diabetes. 28:1039-1057.

25. Karam, J. H., G. M. Grodsky, and P. H. Forsham. 1963. Excessive insulin response to glucose in obese subjects as measured by immunochemical assay. J. Am. Diet. Assoc. 12:197-204.

26. Welle, S. L., and R. G. Campbell. 1983. Normal thermic effect of glucose in obese women. Am. J. Clin. Nutr. 37:87-92.

27. Rothwell, N. J., and M. J. Stock. 1981. A role for insulin in the diet-induced thermogenesis of cafeteria fed rats. Metab. Clin. Exp. 30: 673-678.

28. Balon, T. W., A. Zorzano, M. N. Goodman, and N. B. Ruderman. 1985. Insulin increases thermogenesis in rat skeletal muscle following exercise. Am. J. Physiol. 248:E148-151.

29. Ravussin, E., C. Bogardus, R. S. Schwartz, D. C. Robbins, R. R. Wolfe, E. S. Horton, E. Danforth, Jr., and E. A. Sims. 1983. Thermic effect of infused glucose and insulin in man. Decreased response with increased insulin resistance in obesity and noninsulin-dependent diabetes mellitus. J. Clin. Invest. 72:893-902.

30. Segal, K. R., E. Presta, and B. Gutin. 1984. Thermic effect of food during graded exercise in normal weight and obese men. Am. J. Clin. Nutr. 40:885-1000.

31. Zahorska-Markiewicz, B. 1980. Thermic effect of food and exercise in obesity. Eur. J. Appl. Physiol. 44:231-235.

32. Swindells, Y. E. 1972. The influence of activity and size of meals on caloric response in women. Br. J. Nutr. 27:65-73.

33. Dallosso, H. M., and W. P. T. James. 1984. Whole body calorimetry studies in adult men. 2 . The interaction of exercise and overfeeding on the thermic effect of a meal. Br. J. Nutr. 52:65-72.

34. Davis, J. R., A. R. Tagliaferro, R. Kertzer, T. Gerardo, J. Nichols, and J. Wheeler. 1983. Variations of dietary-induced thermogenesis and body fatness with aerobic capacity. Eur. J. Appl. Physiol. Occup. Physiol. 509:319-329.

35. LeBlanc, J., P. Diamond, J. Côte, and A. Labrie. 1984. Hormonal factors in reduced postprandial heat production of exercise-trained subjects. J. Appl. Physiol. 56:772-776.

36. Newsholme, E. A. 1980. A possible metabolic basis for the control of body weight. N. Engl. J. Med. 302:400-405.

37. Himms-Hagen, J. 1976. Cellular thermogenesis. Annu. Rev. Phy siol. 38:315-351.

38. Nair, K. S., D. Halliday, and J. S. Garrow. 1984. Increased energy expenditure in poorly controlled Type I (insulin-dependent) diabetic patients. Diabetologia. 27:13-16.

39. Waterlow, J. C. 1968. Observations on the mechanism of adaptation to low protein intakes. Lancet. II:1091-1097. 